\title{
International classification trial of AIA set of 100 radiographs of asbestos workers
}

\author{
C E ROSSITER, ' K BROWNE, ${ }^{2} \mathrm{~J}$ C GILSON ${ }^{3}$ \\ From the TUC Centenary Institute of Occupational Health,' London School of Hygiene and Tropical Medicine, \\ London WC1E 7 HT, Cape Industries PLC, ${ }^{2}$ Watford, Herts WDI $7 E G$, and Hembury Hill Farm, ${ }^{3}$ Honiton, \\ Devon EX14 OLA, UK
}

\begin{abstract}
A series of 100 full size radiographs illustrating the range of asbestos related radiographic changes was collected by the Asbestos International Association to provide a demonstration and teaching supplement to the ILO 1980 International Classification of the Radiographic Appearances of Pneumoconioses. Each film was read by 12 experienced readers from ten countries; the readings have been summarised by a median reading, with the range covered by two thirds of the readers. The occupational histories and some relevant clinical information are also available. It is proposed that, in the use of this set, readers should classify each film using the ILO classification rules, particularly without reference to the summary reading or the additional information. Comparing the individual readings by the 12 readers, most of the variation in reading the profusion of small opacities was ascribable only to random variation, with little consistent bias between readers. By contrast, two readers recorded pleural changes much more frequently than their colleagues. This illustrated a major problem with the ILO 1980 Classification. Several others which occurred in this reading trial are also discussed.
\end{abstract}

The ILO 1980 Classification of the Radiographic Appearances of Pneumoconioses provides an internationally accepted means for recording the radiographic appearances for all types of pneumoconiosis.' This formal descriptive scheme permits standardisation by including definitions and a set of 22 standard films with which each film being classified should be compared plus guidelines and notes on the use of the classification.

Nevertheless, only eight of these films are directly relevant to the description of asbestos related radiographic changes. For this reason, the Medical Advisory Panel of the Asbestos International Association (AIA) decided to prepare a supplementary set of demonstration films to show the range of changes occurring in the asbestos industry and to act as teaching material. ${ }^{2}$ The collection was to contain so far as possible examples from all parts of the world and from all sections of the asbestos industry-mining, industrial production, and use. It was also intended to

Accepted 3 August 1987 include a range of radiographic techniques and quality.

\section{Material}

The association collected together some 200 films of asbestos workers from nine countries: Australia, Belgium, Denmark, France, Italy, Japan, Saudi Arabia, the Republic of South Africa, and the United Kingdom. The series included films of employees in the mining industry, in the manufacture of asbestos cement, friction materials, insulation board, and textiles, and in the thermal insulation industry.

From these, 102 films were selected to exhibit a range for almost every specific feature of the ILO 1980 Classification. All categories of parenchymal opacities between $0 / 0$ and $3 / 3$ were represented but with a deliberate bias towards lower categories.

Initially 12 copies of each film were prepared using a new technique that yielded copies of such quality and consistency that no differences could be detected between copies of the same radiograph and there was no noticeable loss of detail compared with the original. 


\section{Reading trials}

Twelve readers* from 10 different countries read the films. An initial subset of 25 films was read by each reader between April and June 1983. A complete record of all these readings, and a cross tabulation of each reader's own readings against the median for each feature of the classification, was sent to each reader. Shortly afterwards, a further set of 78 films (including one from the original set of 25 unintentionally) was read. Two films were generally agreed to be unclassifiable. Exclusion of these and the duplicate reading left 100 films in the final set.

\section{Summary of readings}

So as to permit comparisons between readers, without considering all possible pairs, it was necessary to determine the best estimate of the classification of each film. Reviewing the individual readings, the variability of reading was much greater for some of the films and so a measure of range of reading was also needed.

The 12 readings per film were ranked from most normal to most abnormal for most features of the ILO Classification and the required best estimate was taken to be the median reading, defined as the sixth highest. For any feature, such as thickening of the diaphragm, for which only presence or absence is recorded, the median reading was taken as "present" if six or more readers so recorded it. These definitions of the median reading led to a slight bias towards abnormality but the next highest would have led to the opposite bias. As a measure of range of reading, low and high readings were defined as the third lowest and third highest of the 12 readings. Thus the range from low to high includes two thirds of all the readings.

For the shape and size of small opacities, the median for only those films read as category $0 / 1$ or more was determined, taking into account the equivalence between the sizes of the rounded ( $p, q, r)$ and irregular $(s, t, u)$ opacities. The median shape and size symbols were used for the low and high readings.

It proved necessary on occasion to amend the summary readings when they did not conform strictly to the ILO Classification. This occurred primarily for readings of pleural thickening when the differentiation between "diffuse" and "plaques" was poor. For these, the more common of diffuse and plaques was taken as the median reading.

The disagreement in the recording of symbols was

*The 12 readers were $\mathrm{H}$ Bohlig (Federal Republic of Germany), $M$ Faccini (Italy), B Gandevia (Australia), J C Gilson (UK), I T T Higgins (USA), Y Hosoda (Japan), L M Lacquet (Belgium), N Sargent (USA), A Seaton (UK), G K Sluis-Cremer (Republic of South Africa), A Trepanier (Canada), and P Zivy (France).
Table 1 Distribution of median small opacity readings by profusion, shape, and size

\begin{tabular}{|c|c|c|c|c|c|}
\hline \multirow[b]{2}{*}{ Profusion } & \multirow[b]{2}{*}{ No of films } & \multicolumn{4}{|c|}{ Shape/size } \\
\hline & & $p$ & $q$ & $s$ & $t$ \\
\hline $\begin{array}{l}0 / 0 \\
0 / 1 \\
1 / 0 \\
1 / 1 \\
1 / 2 \\
2 / 1 \\
2 / 2 \\
2 / 3 \\
3 / 2 \\
3 / 3\end{array}$ & $\begin{array}{r}16 \\
16 \\
15 \\
19 \\
12 \\
4 \\
8 \\
5 \\
2 \\
3\end{array}$ & 1 & $\begin{array}{l}1 \\
1\end{array}$ & $\begin{array}{r}9 \\
11 \\
6 \\
7 \\
2 \\
2 \\
2 \\
2\end{array}$ & $\begin{array}{r}6 \\
4 \\
13 \\
5 \\
1 \\
4 \\
3 \\
2 \\
1\end{array}$ \\
\hline Total & 100 & 1 & 3 & 41 & 39 \\
\hline
\end{tabular}

such that only tarely did over half the readers agree. For the median summary reading, all symbols were included when four or more readers agreed. No comments were included in the summary readings, but the comments were used in the preparation of the booklet provided with the set of films.

\section{AIA demonstration set of radiographs}

The demonstration set of 100 radiographs* consists of copies prepared to the same quality as those included in the reading trial. In addition, a booklet gives on one page the median, low, and high readings for each film, permitting any reader to compare a personal reading with these. On the obverse page, an occupational history is given, together with some relevant clinical information and a synopsis of the comments by the 12 readers. In using these films as a learning aid a reader is expected to assess each film as described in the ILO Classification without prior view of the additional detail provided. This prevents the reading bias associated with knowledge of age and occupational history. These 100 radiographs provide enough material to learn how to use the classification for asbestos exposed individuals and to check the reading levels against the median and range of the 12 international readers.

\section{Results}

SMALL OPACITIES

Table 1 shows the distribution of the median values for the profusion of small opacities. As intended in the original selection, most of the radiographs were in the lower categories although they ranged up to midcategory 3 . All but four of the 84 positive films were recorded as being of irregular shape and none of the

*Details available from the Asbestos International Association, 68 Gloucester Place, London WIH 3HL, UK. 
Table 2 Profusion of small opacities: distribution by reader relative to median reading

\begin{tabular}{|c|c|c|c|c|c|c|c|c|c|c|c|c|}
\hline \multirow[b]{2}{*}{ Reader } & \multicolumn{5}{|c|}{$\begin{array}{l}\text { Subcategories } \\
\text { below median reading }\end{array}$} & \multirow[b]{2}{*}{0} & \multicolumn{5}{|c|}{$\begin{array}{l}\text { Subcategories } \\
\text { above median reading }\end{array}$} & \multirow{2}{*}{$\begin{array}{l}\text { More than } 1 \\
\text { subcategory } \\
\text { from median }\end{array}$} \\
\hline & $\geqslant 5$ & 4 & 3 & 2 & $I$ & & 1 & 2 & 3 & 4 & $\geqslant 5$ & \\
\hline \multirow[t]{2}{*}{$\begin{array}{r}4 \\
8 \\
7 \\
5 \\
6 \\
2 \\
10 \\
1 \\
3 \\
9 \\
12 \\
11\end{array}$} & 2 & $\begin{array}{l}1 \\
2 \\
2 \\
1\end{array}$ & $\begin{array}{l}9 \\
4 \\
5 \\
6 \\
4 \\
6 \\
1\end{array}$ & $\begin{array}{r}15 \\
14 \\
12 \\
5 \\
8 \\
11 \\
4 \\
7 \\
7 \\
2 \\
1 \\
2\end{array}$ & $\begin{array}{r}35 \\
26 \\
27 \\
20 \\
22 \\
21 \\
18 \\
14 \\
12 \\
11 \\
11 \\
7\end{array}$ & $\begin{array}{l}34 \\
44 \\
41 \\
46 \\
45 \\
36 \\
50 \\
49 \\
46 \\
55 \\
39 \\
31\end{array}$ & $\begin{array}{l}3 \\
7 \\
14 \\
13 \\
16 \\
12 \\
18 \\
16 \\
22 \\
21 \\
27 \\
30\end{array}$ & $\begin{array}{r}2 \\
1 \\
1 \\
3 \\
3 \\
5 \\
5 \\
9 \\
9 \\
7 \\
16 \\
19\end{array}$ & $\begin{array}{l}1 \\
1 \\
1 \\
2 \\
5 \\
4 \\
3 \\
4 \\
3 \\
1 \\
7\end{array}$ & $\begin{array}{l}1 \\
1 \\
2\end{array}$ & $\begin{array}{l}1 \\
1 \\
2\end{array}$ & $\begin{array}{l}28 \\
23 \\
18 \\
21 \\
17 \\
31 \\
14 \\
21 \\
20 \\
13 \\
23 \\
32\end{array}$ \\
\hline & 3 & 6 & 38 & 88 & 224 & 516 & 199 & 80 & 32 & 9 & 5 & $21.8 \%$ \\
\hline
\end{tabular}

median readings was of size " $r$ " or " $u$." Of the 970 individual positive readings, only six were of $r$ and nine of $u$.

The readers were ranked in order of under-reading to over-reading relative to the median (table 2). The overall impression is that differences between readers are not large compared with variability in reading. Typically one in five readings was two or more subcategories deviant from the median. The range of median readings was just above the lower limit of subcategory $1 / 0$ (reader 4 ) to just below the upper limit of subcategory $1 / 1$ (reader 11 ), less than two subcategories difference. Nevertheless, these discrepancies lead, for example, to a range of $16 \%$ to $38 \%$ in the porportion of films recorded as subcategory $2 / 1$ or more. The range of readings more than one subcategory from the median varied from $13 \%$ to $32 \%$ with four readers less than $20 \%$.

Poor film quality has been considered as a possible cause for discrepancy in readings. Of the 18 films for which there were the greatest discrepancies, however, $13(72 \%)$ were recorded as film quality 1 . This does not differ significantly from the $79 \%$ overall. These 18 films included more of those in the higher categories, $13(72 \%)$ being $1 / 1$ or higher compaed with $76 \%$ of the 21 poor quality films, but only $53 \%$ of the whole series.

A check of the 23 individual readings that were more than three subcategories deviant from the median suggest that seven reflected the biases between the readers. Two films accounted for another seven of the discrepancies, one being a poor quality film with a range of reading from $0 / 1$ to $3 / 3$ (film 12) and the other (film 59) providing a good example of the occasional great difficulty in separating parenchymal from pleural changes. Reader 1 twice recorded much higher readings but his comments noted "parenchyma normal but pleural opacities read as if parenchymal" and "small opacities almost certainly pleural thickening." On the one occasion that reader 5 read much higher, he recorded parenchymal changes unilaterally, whereas nine of his colleagues recorded pleural changes. There was also an example of the problem (film 79) of averaging over affected zones, as required by the ILO 1980 Classification. This led to one reading of $3 / 3$ in the lower zones only, with all other readings lower with more (usually 4) affected zones. It is not possible to account for the remaining discrepancies similarly, yielding an aberrant reading incidence of only about five in 1200 readings.

\section{LARGE OPACITIES}

None of the median readings indicates the existence of large opacities in this series. A large opacity, however, was generally accepted as present on one radiograph (film 45). There were four readings of "B," one of " $A$," two readers included " $\mathrm{CA}$ " as a symbol, and there were three additional relevant comments. There were 12 individual readings of $A$ for 10 of the remaining films.

\section{PLEURAL THICKENING}

The median readings of pleural thickening were positive bilaterally for 33 films and unilaterally for 19 , and negative for the remaining 48. In table 3 the readers have been ordered in terms of relative underreading or over-reading. Five of the readers underread frequently, but reader 6 , and to a lesser extent reader 11 , recorded pleural thickening much more frequently.

Reader 6 recorded pleural thickening for all but four films and for each of these his comment was that radiographic technique "made it difficult to read the pleura." For 12 films, he was the only reader to record pleural thickening. Reader 11 read 78 films as positive 
Table 3 Pleural thickening: distribution by reader relative to median

\begin{tabular}{|c|c|c|c|c|c|c|}
\hline \multirow[b]{2}{*}{ Reader } & \multicolumn{2}{|c|}{ Under-reading } & \multirow[b]{2}{*}{0} & \multicolumn{2}{|c|}{ Over-reading } & \multirow{2}{*}{$\begin{array}{l}\text { Bilateral } \\
(\%)\end{array}$} \\
\hline & Bilateral & Unilateral & & Unilateral & Bilateral & \\
\hline \multirow{10}{*}{$\begin{array}{r}7 \\
5 \\
2 \\
4 \\
1 \\
10 \\
8 \\
12 \\
9 \\
3 \\
11 \\
6\end{array}$} & 7 & 15 & 76 & 2 & & 7 \\
\hline & $\begin{array}{l}6 \\
7\end{array}$ & $\begin{array}{l}15 \\
12\end{array}$ & $\begin{array}{l}76 \\
75\end{array}$ & 3 & 3 & 6 \\
\hline & 6 & 6 & 87 & 3 & 3 & $\begin{array}{r}10 \\
6\end{array}$ \\
\hline & 3 & 15 & 74 & 8 & & 3 \\
\hline & $\begin{array}{l}3 \\
2\end{array}$ & $\begin{array}{l}8 \\
5\end{array}$ & 82 & 6 & 1 & 4 \\
\hline & 4 & 10 & 70 & 12 & 4 & 8 \\
\hline & 1 & 1 & 90 & 8 & & 1 \\
\hline & & 10 & 68 & 17 & 3 & 5 \\
\hline & & 1 & $\begin{array}{l}60 \\
38\end{array}$ & $\begin{array}{l}21 \\
22\end{array}$ & $\begin{array}{l}18 \\
40\end{array}$ & $\begin{array}{l}18 \\
40\end{array}$ \\
\hline & 41 & 98 & 882 & 107 & 72 & 9.4 \\
\hline
\end{tabular}

compared with the range of $38-60$ for the remaining ten readers.

\section{PLEURAL CALCIFICATION}

The prevalence of pleural calcification in this demonstration set of radiographs is much less than that for pleural thickening. The median readings were positive for only 18 films, nine bilaterally. As shown in table 4, however, there were still quite pronounced differences between the readers, with readers 6 and 11 again overreading relative to the others.

These two readers read pleural calcification for 29 and 27 films respectively. The range for the other readers was 14-25. No pattern to account for the differences was noticeable from the readers' comments.

\section{Discussion}

It must be emphasised that, in preparing this set of 100 demonstration radiographs, there was no intention to create additional or alternative standard films to those supplied by ILO. The ILO films have been chosen to define the categories of small opacities and to illustrate the larger opacities and pleural appearances of the pneumoconioses. Inevitably, the ILO standards are somewhat atypical of radiographs of dust exposed workers because of the need for standards showing particular features uncomplicated by other appearances. The ILO Classification was originally developed to categorise parenchymal changes in coalworkers and did not record pleural thickening in detail. When the UICC/Cincinnati Classification was absorbed into the ILO Classification, the appearances of pleural thickening were illustrated by two films, but no standards for severity of thickening were included. As the unthickened pleura may be seen in some films, particularly in the upper zones, there is at present opportunity for wider variation in recording pleural

Table 4 Pleural calcification: distribution by reader relative to median

\begin{tabular}{|c|c|c|c|c|c|c|}
\hline \multirow[b]{2}{*}{ Reader } & \multicolumn{2}{|c|}{ Under-reading } & \multirow[b]{2}{*}{0} & \multicolumn{2}{|c|}{ Over-reading } & \multirow{2}{*}{$\begin{array}{l}\text { Bilateral } \\
(\%)\end{array}$} \\
\hline & Bilateral & Unilateral & & Unilateral & Bilateral & \\
\hline $\begin{array}{r}7 \\
3 \\
10 \\
12 \\
1 \\
8 \\
5 \\
2 \\
9 \\
4 \\
11 \\
6\end{array}$ & & $\begin{array}{l}5 \\
4 \\
3 \\
3 \\
4 \\
3 \\
1 \\
1 \\
1 \\
2\end{array}$ & $\begin{array}{l}94 \\
94 \\
95 \\
94 \\
91 \\
93 \\
97 \\
92 \\
88 \\
88 \\
85 \\
87\end{array}$ & $\begin{array}{r}1 \\
2 \\
2 \\
3 \\
4 \\
3 \\
3 \\
7 \\
11 \\
9 \\
9 \\
8\end{array}$ & $\begin{array}{l}2 \\
4 \\
5\end{array}$ & $\begin{array}{l}0 \\
0 \\
0 \\
0 \\
1 \\
1 \\
0 \\
0 \\
0 \\
2 \\
4 \\
5\end{array}$ \\
\hline & & 27 & 1098 & 62 & 13 & $1 \cdot 1$ \\
\hline
\end{tabular}


changes. This was confirmed in this trial. There is a need to improve this part of the classification.

This set of 100 films shows the range worldwide of appearances of radiographs of asbestos exposed workers including the frequent co-occurrence of parenchymal and pleural changes. Although the poorest quality films have been excluded, the set also includes a range of quality likely to be produced by all but the best controlled radiography equipment. Thus the original intention of providing typical films of asbestos exposed workers as a companion to the ILO set of standard films for teaching and illustrative purposes has been met.

The UICC/Cincinnati Classification of the radiographic appearances of pneumoconioses ${ }^{3}$ was developed from the ILO 1958 Classification to cover appearances seen in asbestos exposed individuals, and itself was the precursor of the present 1980 scheme. Three of the readers in this study were also engaged in repeatability trials of that classification. ${ }^{4}$ Then, $63 \%$ of all readings were of category $0 / 1$ or more with the prevalences for the three readers in common being $84 \%, 51 \%$, and $48 \%$. The range for the 12 readers was $30-91 \%$. For comparison, the range of prevalence of category $1 / 1$ or more in this study was $29-65 \%$ (average 53\%), so that it does appear that the interreader variability has reduced. For the particular three readers the prevalences are $65 \%, 46 \%$, and $51 \%$ respectively, also suggesting an increase in concordance.

The 12 readers from 10 countries were all familiar with the ILO Classification but much of their use was probably for rather different purposes: some mainly in epidemiology, others for routine surveillance of dust exposed groups, and others as part of compensation assessment. The text of the Classification states "the classification does not imply legal definitions of pneumoconiosis for compensation purposes nor set nor imply a level at which compensation is payable." In some countries, however, the classification has been incorporated in legislation and points on the scales linked with administrative action. It seems possible, though we have no direct evidence for this, that those using the scheme for purposes other than epidemiology may have biases in their reading patterns relative to those whose main interest is epidemiological.

The principle introduced in the 1950 revision, and continued since, is that the aim is to provide a means of recording the continuum of changes from category 0 to category 3 , and not to dichotomise into those with and without a particular radiographic appearance. The value of this principle has become apparent now that it is recognised that cigarette smoking can influence the profusion of small opacities at the bottom end of the scales.
A further reason for variations between readers is their strictness of adherence to the instructions for the use of the 12 point scale for the profusion of small opacities; these are to classify into one of the four main categories 0 to 3 and if, during the process, a neighbouring category is "seriously considered," to record this after the formal category. Thus if a film is seen to be less than the category 1 standard but category 0 is not seriously considered, then the classification should be $1 / 1$, not $1 / 0$. Failure to apply these strict rules leads to disagreements between readings because it affects the numbers of films put into each mid-category and its immediately adjacent categories (P D Oldham, personal communication).

One of the readers who was concerned about his deviation from the median readings noted that he did not obey this rule for recording of profusion of small opacities. Instead he had been dividing each major category into three parts directly. Subsequently, he reread the films using the formal rules of the ILO Classification and his readings then differed far less from the median (I T T Higgins and J C Gilson, personal communication).

For pleural thickening, the range of positive readings in the UICC/Cincinnati Classification reading trial was $20-57 \%$, but this has now increased to $38-$ $96 \%$ due, primarily, to a different pattern of reading by reader 6 . That reader has a long standing interest in pleural appearances as confirmed by his comments during this reading trial, and this is reflected in his assessment of what should be recorded as pleural thickening. He seems to have a special eye for pleural changes as he also recorded more pleural calcification than any other reader.

Since 1950, the ILO Classification has been revised about every 10 years. The scope and precision have been improved but further improvements are possible. The classification has been used in hundreds of papers. Much of the dose response data on which standards are set to control the occurrence of pneumoconiosis and associated disability depend on the use of the classification. The scheme may be used for the biological monitoring of dust concentrations below those causing any detectable disability or loss of life expectancy. There are therefore strong reasons for continuing the development of a scheme that has been increasingly widely used since 1950 .

The extensive comments* made by the 12 readers highlight the problems still occurring with the classification of pleural changes. The text of the ILO Classification is subject to varied interpretation, even to the extent that several different recording forms are in use worldwide which are incompatible for pleural

*A synopsis of these comments on the ILO Classification, and its use, may also be obtained from the Asbestos International Association. 
thickening. Additionally, this reading trial has shown that these interpretations can appreciably affect recorded prevalences of pleural changes. Without improved standardisation, the classification cannot fulfil its purposes. This is also particularly important in the differentiation between diffuse pleural thickening and uncalcified pleural plaques. The aim of classification is to separate visceral and parietal pleural thickening because of the differences in natural history and the relation to pleural calcification.

There were several comments about the definition of film quality which will need to be debated before the next revision. Should quality 1 be reserved for "perfect" films? Should there be definitions of the terms "parenchyma visible" and "pleura visible"? Should information on film quality be given objectively by densitometry, as described in the technical appendix of the ILO Classification? How much adjustment should readers attempt to make for perceived film quality faults, particularly if films are too white or too black?

The readers made fewer comments about the classification of small parenchymal opacities. There is, however, a need to review the use of the zones of the lung for recording site, especially when there is a major difference in profusion by zone. Should the existing rules for "averaging" be changed? Should profusion be recorded separately for each of six, or four, zones?

There was also some concern that the ILO Classification was not always adequate to describe features believed to be important by some readers. For example, significant associations have been reported ${ }^{5}$ be- tween reduction of lung function and the presence of thickened bronchial walls and abnormal peripheral markings. Yet routine use of the classification would not provide the evidence to corroborate these findings. The discussion will need to centre on the balance between complexity and practicality.

Particular thanks are due to the readers who participated in this international reading trial and to Sir Neville Stack and Mr Albert van Rosse of the Asbestos International Association for their help in the organisation. The expertise of Mr D Jenkins in copying the 100 films is also gratefully acknowledged.

\section{References}

1 International Labour Office. ILO 1980 classification of the radiographic appearances of the pneumoconioses. Geneva: International Labour Office, 1980. (Occupational Safety and Health series No 22 (rev 1980).)

2 Browne K, Lepoutre J, Mansour F, Murray R, Gilson JC, Rossiter CE. Radiology of asbestos-related disease. A supplement to the ILO standard set and a check on its validity. In: Ulmer WT, ed. Proceedings of the VI international conference on pneumoconiosis, Bochum, 1983. Bochum: Bergbau-Berufsgenossenschaft, 1984: 882-8.

3 UICC Committee. UICC/Cincinnati classification of the radiographic appearances of pneumoconioses. Chest 1970;58:57-67.

4 Rossiter CE. Initial repeatability trials of the UICC/Cincinnati classification of the radiographic appearances of pneumoconioses. Br J Ind Med 1972;29:407-19.

5 Musk AW, Gandevia B, Williams B. Respiratory function and the chest radiograph: an epidemiological study of the significance of minor radiographic abnormalities. Aust NZ J Med 1978;8:7-13. 